\title{
Epidemiology of Hepatitis E in Pregnant Women and Children in Iran: A General Overview
}

\author{
Reza Taherkhani ${ }^{1,2}$ and Fatemeh Farshadpour*1,3 \\ ${ }^{1}$ Department of Microbiology and Parasitology, School of Medicine, Bushehr University of Medical Sciences, Bushehr, Iran; \\ ${ }^{2}$ Persian Gulf Biomedical Research Center, Bushehr University of Medical Sciences, Bushehr, Iran; ${ }^{3}$ Persian Gulf Tropical Medicine \\ Research Center, Bushehr University of Medical Sciences, Bushehr, Iran
}

\begin{abstract}
From an epidemiological point of view, hepatitis $\mathrm{E}$ is an old infection in Iran, but only recently has its importance as a public health concern been considered from research and public health standpoints. As such, there is still a long road ahead to clarify the real burden of hepatitis E virus (HEV) infection in Iran. According to the available epidemiological studies, the seroprevalence of HEV infection among pregnant women is between $3.6 \%$ and $7.4 \%$, and among Iranian children is between $0.9 \%$ to $8.5 \%$, varying by geographic regions within the country and directly dependent upon the sanitary status of each. In addition to evaluating the sanitation level of a society, community-based seroprevalence studies of HEV infection demonstrate the most prevalent risk factors, the major routes of transmission, and the epidemiological patterns of HEV among that country's population. In this review, the current knowledge about the pathogenesis and epidemiology of HEV infection in pregnant women and children in Iran, as well as the recent advances in diagnosis, prevention and treatment of HEV infection have been summarized.
\end{abstract}

(c) 2016 The Second Affiliated Hospital of Chongqing Medical University. Published by XIA \& HE Publishing Inc. All rights reserved.

\section{Introduction}

Hepatitis E virus (HEV) infection is generally an enterically transmitted viral hepatitis with asymptomatic or acute selflimited manifestations. ${ }^{1}$ However, progression to fulminant liver failure has also been reported in high-risk groups, such as pregnant women and patients with underlying liver problems. ${ }^{1-7}$ Chronicity is rare and is mostly observed in immunocompromised and immunosuppressed patients, such as

Keywords: Hepatitis E virus; Pregnant women; Children; Epidemiology; Iran. Abbreviations: HEV, hepatitis E virus; HIV, human immunodeficiency virus; WHO, World Health Organization; TGF- $\beta$, transforming growth factor-beta; NF-кь, nuclear factor-kappa B; Th2, T helper 2; HCG, human chorionic gonadotropin; Th1, T helper 1; FLF, fulminant liver failure; HLA, human leukocyte antigen; MHC, major histocompatibility complex; NAT, nucleic acid amplification techniques; AST, aspartate aminotransferase; ALT, alanine aminotransferase; PEG-IFN, pegylated interferon.

Received: 29 March 2016; Revised: 01 August 2016; Accepted: 18 August 2016 DOI: $10.14218 / \mathrm{JCTH} .2016 .00013$.

*Correspondence to: Fatemeh Farshadpour, Department of Microbiology and Parasitology, School of Medicine, Bushehr University of Medical Sciences, Moallem Street, P. O. Box 3631, Bushehr 7514633341, Iran. Tel: +98-9171712653, Fax: +98-7714550235, E-mail: f.farshadpour@yahoo.com patients who have received organ transplant, are infected with human immunodeficiency virus (HIV) or suffer from haematological malignancies. ${ }^{5,8-14}$ Therefore, despite the benign clinical presentation of hepatitis $\mathrm{E}$ in the general population, it is considered as an important health concern, especially in those high-risk populations.

According to the epidemiological data, 3.3 million acute cases and 20 million new cases of hepatitis $E$ are diagnosed each year globally. ${ }^{3,15}$ Despite the mortality rate of $1-2 \%$ in the general population, ${ }^{16} 10-25 \%$ of pregnant women and $>75 \%$ of patients with underlying liver disease lose their lives due to the HEV infection. ${ }^{17,18}$ According to a report from the World Health Organization (WHO), 56600 deaths occur per year due to HEV-related hepatic failure. ${ }^{19}$ Overall, one-third of the world's population has been infected with $\mathrm{HEV}^{20,21}$

HEV is a small virus in the family Hepeviridae, with a positive single-stranded RNA genome and non-enveloped icosahedral capsid..$^{5,9,22,23}$ The genome consists of three partially overlapping open reading frames (Fig. 1). ${ }^{5,24,25} \mathrm{HEV}$ is usually transmitted via the faecal-oral route, particularly through contaminated food and water supplies. However, transmission through haemodialysis, organ transplantation, sexual intercourse, placenta, blood and blood product transfusion is also possible, but the importance of each is unknown. ${ }^{1,17,26}$ Only four genotypes capable of affecting human beings have been identified thus far. ${ }^{3,27}$ These four genotypes have been classified into the genus Orthohepevirus and the species Orthohepevirus $A_{1}^{1,28}$ and they differ in their mode of transmission, pathogenicity, severity, mortality rates, geographical and age distribution. . $^{1,17,26,29,30}$

Genotypes 1 and 2 affect human beings and are responsible for large epidemics or acute outbreaks in developing countries. These outbreaks occur due to contamination of drinking water following heavy rainfall or flooding, and are more frequently observed among young adult males. ${ }^{1,3,5,13,26,29,31}$ Meanwhile, genotypes 3 and 4 use an animal reservoir and are mostly transmitted via consumption of contaminated meat; these two genotypes are the causative agents of locally-acquired sporadic HEV infections in developed countries and mostly affect middle-aged to elderly males. $1,3,5,13,29,31-33$ These variations in the epidemiological patterns of HEV reflect differences in the level of sanitation, lifestyle, risk factors and status of public health in the different groups and regions across the globe. ${ }^{14,34-36}$ Therefore, it is important to study the epidemiological patterns of hepatitis $E$ in the different groups and regions to determine the burden of this viral infection. 

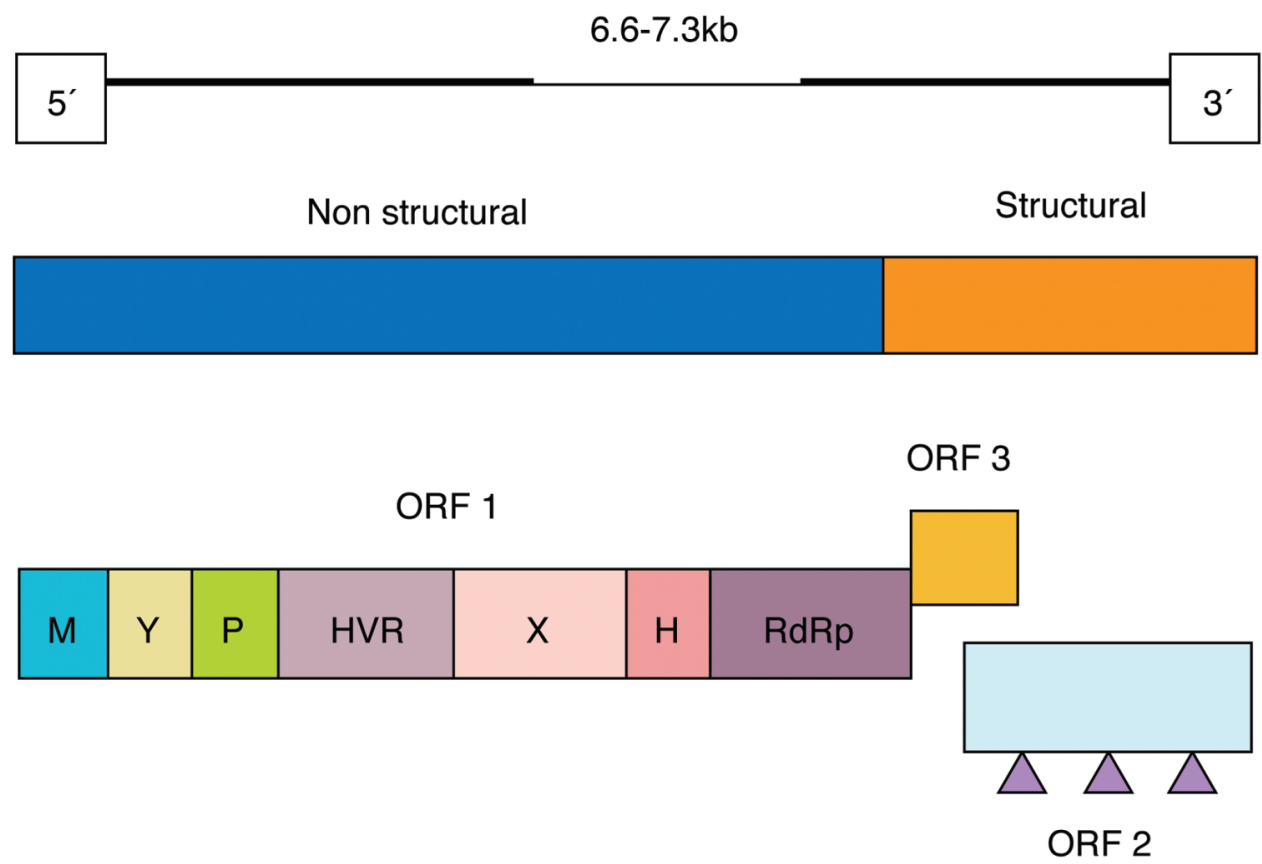

Fig. 1. Molecular structure of hepatitis E virus. ${ }^{1}$ (Adapted from Fig. 1 of reference 1 , with permission of the publisher).

Abbreviations: M, methyltransferase; Y, Y domain; P, papain-like cysteine protease; HVR, hypervariable region; X, macro-domain; H, helicase; RdRp, RNA-dependent RNA polymerase; Triangle, glycosylation site.

In Iran, HEV infection is endemic, but the epidemiology of this infection in two of the most vulnerable groups-pregnant women and children-remains unclear. Therefore, this study was conducted to provide a general overview of the pathogenesis and epidemiology of hepatitis $E$ in these two groups in Iran.

\section{HEV in pregnant women in Iran}

HEV infection is not only generally a benign self-limited disease, but it can also adversely affect pregnant women and lead to fulminant hepatic failure, especially during the second and third trimesters, subsequently lowering survival of mothers and their fetuses. ${ }^{37-41}$ Overall, it is reported that $0 \%$ to $73 \%$ of mortalities in pregnant women are attributed to HEV infection in the endemic regions, representing $0 \%$ in Egypt, 3.4\% in South India, $42 \%$ in Ethiopia and 39.1-73\% in North India. ${ }^{39}$ Besides maternal complications, HEV also causes serious consequences to the foetus following transplacental transmission, which varies in severity from low birth weight, prematurity, mild anicteric neonatal hepatitis or jaundice at birth with full recovery to miscarriage, stillbirth, preterm labour, perinatal death or neonatal death soon after birth. $1,27,29,37,38,40,42$ No extrahepatic manifestations or chronic carrier state has been reported in children born to mothers with HEV infection. ${ }^{27,38}$

Such severe complications in pregnancy are not seen with the other known hepatitis viruses. ${ }^{5,22,40}$ Although the exact mechanism of this excess severity of hepatitis $E$ in pregnancy has not yet been determined, it seems that a combination of host and viral factors contributes to the pathogenesis of hepatitis $\mathrm{E}$ during pregnancy. ${ }^{1,37,39}$

Pregnancy is accompanied by significant changes in maternal hormonal and immunological responses to sustain the foetus. ${ }^{39,40}$ These immunological changes include inhibition of cell-mediated immunity through secretion of transforming growth factor-beta (TGF- $\beta$ ) and IL-4 and IL-10 cytokines, down-regulation of nuclear factor-kappa B (NF-кB), reduction in $\mathrm{T}$ cell activity and cytokine production, along with an alteration in cellular immune regulation towards an increase in CD8 cell counts and a decrease in CD4 cells with predominant T helper 2 (Th2) responses; all of these result in systematic suppression of the maternal immune system and subsequently increase susceptibility to infections. ${ }^{1,37,39,40}$ Moreover, the steroid hormones including beta-HCG (human chorionic gonadotropin), oestrogen and progesterone increase during pregnancy. ${ }^{5,39,40,42}$ These hormones have direct inhibitory effects on hepatocytes, cell-mediated immunity, T helper 1 (Th1) cell development and $B$ cell production; moreover, through the decreased expression of NF-кB, they promote lymphocyte apoptosis. In addition, these hormones induce viral replication and the development of Th2 cells. ${ }^{37,39,40,42}$

Although the above-mentioned hormonal and immunological changes physiologically occur in normal pregnancy, when pregnancy is accompanied by HEV infection these changes increase. ${ }^{39,40,42}$ As such, HEV-infected pregnant women may suffer from decreased activity or absence of the p65 component of the NF-кB complex, which likely induces acute liver damage. ${ }^{39,40}$ Moreover, HEV appears to have a direct cytopathogenic effect on hepatic cells or immune-mediated pathogenesis through induction of host inflammatory responses, which may result in destruction of hepatocytes. ${ }^{1,43}$ Although Th2 responses are predominant in normal pregnancy, a strong cytotoxic immune response may be induced through an alteration in T helper responses towards Th1 following HEV infection aimed at reducing the high viral load, but which in turn results in lower foetal survival rates. ${ }^{42}$ 
Foetal infection with HEV will enhance the severity of infection and risk of liver failure in the mother. ${ }^{38-40}$ Moreover, the inhibitory effects of steroid hormones on hepatocytes can result in hepatic dysfunction when pregnancy is accompanied by HEV infection. ${ }^{40,42}$ Overall, it seems that HEV by itself does not induce these changes and requires pregnancy as a physiological factor to enhance the risk of hepatic damage. Therefore, pregnant women with hepatitis $\mathrm{E}$ are at an increased risk for developing liver failure. ${ }^{39,40}$

It seems that viral load and genotype can influence severity of HEV infection during pregnancy. As such, high viral load, along with genotypes 1 and 2, known as the more virulent genotypes, contribute to the development of fulminant liver failure (FLF). ${ }^{1,5,37,38,42}$ In addition, poor maternal nutrition and the use of herbal medicines to relieve symptoms of HEV infection due to side effects are associated with increased severity of hepatitis E. ${ }^{39,40,42,43}$ Finally, the role of genetic factors, such as variation in human leukocyte antigen (HLA) alleles in different geographical regions, should also be considered in the pathogenesis of HEV infection during pregnancy. 39,40

An endotoxin-mediated effect has been proposed as another probable factor in the pathogenesis of FLF in pregnancy. In this process, the Kupffer cells, a type of liver sinusoidal cells, are destroyed by HEV, negating their ability to protect the liver cells against endotoxin derived from gramnegative bacteria of the intestinal tract. ${ }^{40}$ In addition, release of prostaglandins due to HEV infection can indirectly damage hepatocytes through attraction of neutrophils, which result in inflammation, oedema and cholestasis in liver. ${ }^{40}$

In endemic regions, the incidence and severity of HEV infection in pregnant women are much higher than that in non-pregnant women and men, with reported maternal mortality rates of $30-100 \%$ in the various studies. ${ }^{1,39,40,44}$ The rate of vertical transmission from mother to foetus varies from $30 \%$ to $79 \%$, and sometimes up to $100 \%$, in the different studies as well. ${ }^{27}$ In addition, mother-to-child transmission via breastfeeding is also possible and mostly occurs during the acute phase of infection. ${ }^{37}$ In developing countries, HEV infection accounts for approximately 3000 stillbirths annually. ${ }^{5,37}$ Interestingly, the above-mentioned epidemiological pattern is not observed in all endemic countries. ${ }^{5,44}$ In Egypt, for example, despite reporting high seroprevalence of HEV among pregnant women, the disease follows a mild or asymptomatic course, with very low mortality. ${ }^{38-40,44}$ However, the exact reason behind this benign pathogenicity remains unclear, but might be related to the presence of a highly contagious but less virulent strain of the HEV genotype predominantly found in Egypt ${ }^{5,22,38-40,44}$ or possibly the differences in major histocompatibility complex (MHC) phenotypes in this country as compared to the other endemic areas. ${ }^{5}$ It can also be explained by the high levels of previous exposure to HEV in early childhood, resulting in long-lasting immunity and probably attenuated infection upon re-exposure to HEV in adulthood. ${ }^{5,38-40}$ Similar findings have been reported in the United States (US) and Europe, where there is no difference in the severity of HEV infection in pregnant women compared to that in nonpregnant women, ${ }^{38,39,42}$ while HEV seroprevalence is considerably high but most HEV infections are asymptomatic or remain undiagnosed. ${ }^{44}$

In Iran, however, the epidemiology is even more unclear. There are few reports on the seroprevalence of HEV infection among pregnant women in Iran. In the available studies, however, the seroprevalence of HEV infection varies from $3.6 \%$ to $7.6 \%,{ }^{45-49}$ which is more or less similar to HEV seroprevalence in the general population of Iran (Table 1 and Fig. 2). Moreover, age, level of education, parities, stage of gestation and the number of family members have been identified as risk factors for HEV seropositivity among these reported pregnant women. ${ }^{46-48}$ In particular, increasing gestational age, lower education, third trimester of pregnancy and more parities are associated with high seroprevalence of HEV infection among the pregnant women. ${ }^{46-48}$ Compared to the other endemic countries, ${ }^{50-52}$ the seroprevalence of HEV infection among Iranian pregnant women is low. ${ }^{45,47,48}$ In addition, there is a considerable difference in rate of HEV seroprevalence between Iran and neighbouring countries such as the United Arab Emirates $(20.0 \%)^{53}$ and India $(33.67 \%){ }^{50}$ meanwhile, it is similar to that reported for Turkey $(7.0 \%) .54$

Considering the adverse effects of HEV infection on pregnancy outcomes, prevention strategies, appropriate precautions and training programs regarding the possible routes of exposure to HEV as well as routine screening for HEV infection before and during pregnancy are needed to reduce the occurrence and adverse consequences of HEV infection in the pregnant population. ${ }^{46,47}$ Overall, the importance of HEV infection during pregnancy is underestimated in Iran and there are no current data on the rate of maternal mortality in Iran.

\section{HEV in children in Iran}

There are few studies on the seroprevalence of HEV infection among children in Iran. In those studies, seroprevalence rates vary from $0.9 \%$ to $8.5 \%$ (Table 1 and Fig. 2). ${ }^{55-59}$ Although the seroprevalence of HEV among children in Iran is not as high as reported for Nepal (16\%), Tibet (23.8\%) and India $(17.75 \%-24.7 \%),{ }^{27}$ it is still considerably higher than for Taiwan $(0.3 \%)$, Mongolia $(0.6 \%)$, Greenland $(0.0 \%)$, Korea $(0 \%-1 \%)$ and Argentina $(0.15 \%) .{ }^{27}$ Globally, the highest HEV prevalence, ranging from $36.2 \%$ to $75.5 \%$, has been reported for children in Egypt. ${ }^{27}$

The sero-epidemiological patterns of HEV infection among children in Iran are similar to those observed in other endemic countries, such as Bangladesh, Mexico, China, Turkey and Venezuela. ${ }^{27}$ Those studies have shown that the HEV seroprevalence is low in early childhood but increases with age. ${ }^{27,55,57}$ Egypt is an exception, with the majority of children being exposed to HEV in early life, as evidenced by $65 \%$ of children under 10 years of age being seropositive. ${ }^{27,60}$ Globally, $<10 \%$ of children aged under 10 years are HEV seropositive. $^{27}$

Most cases of HEV infection among children are subclinical. $27,39,55$ Despite this asymptomatic feature, the mortality rate is considerably high in children with jaundice; one study in Uganda reported a high mortality rate among icteric children, which was even higher than the mortality rates reported among the pregnant women in that country. ${ }^{16}$ However, there is no report on the mortality rate of HEV infection among children in Iran.

Some studies have evaluated the trends in seroprevalence of HEV infection among children over time and showed a slight but not significant increase in HEV seropositivity. One study from India indicated a significant increase in HEV seroprevalence over time. ${ }^{27}$ However, due to inadequate 


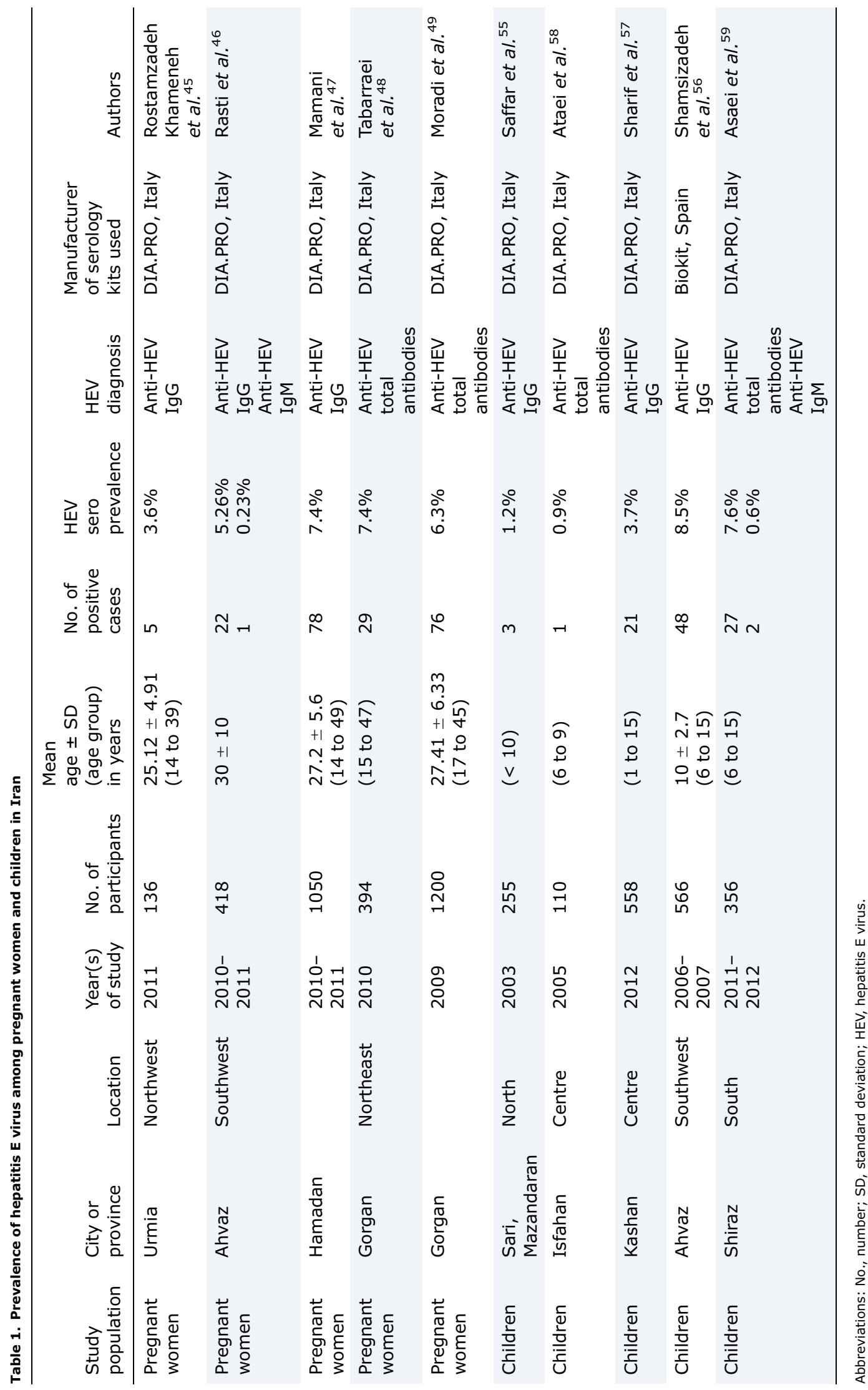


Taherkhani R. et al: HEV in pregnant women and children

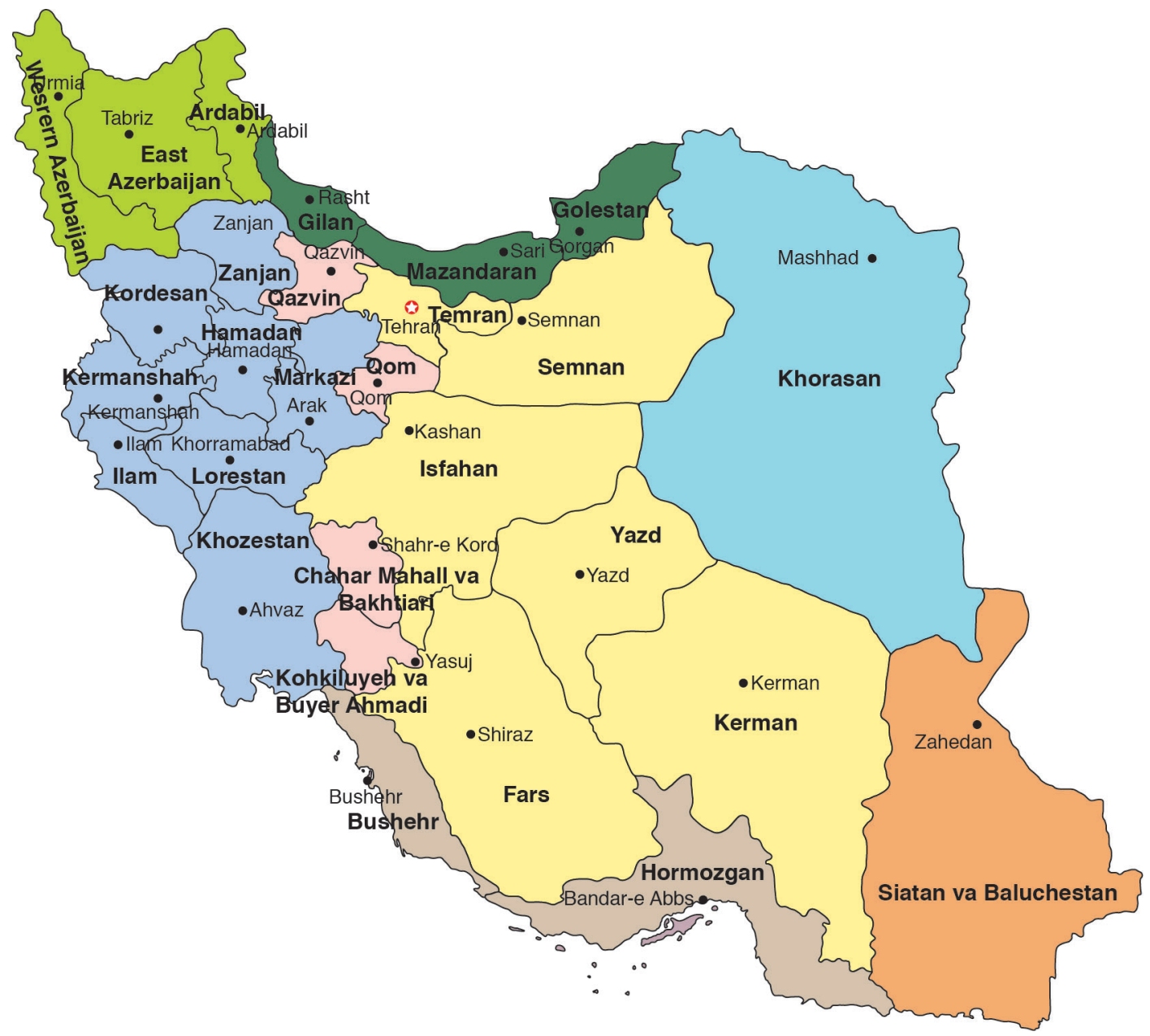

Fig. 2. Map of Iran.

studies in Iran, the changes in trends of HEV seroprevalence over time remain unclear.

Children are representative of a group at risk of HEV infection. ${ }^{27}$ Recent studies have shown that the seroprevalence of HEV infection among children is related to sanitary status of different parts of the country. ${ }^{55,61}$ Considering the fact that contaminated drinking water supplies and inappropriate sewage disposal systems are associated with HEV seropositivity, the faecal-oral route is the main route of HEV transmission among Iranian children. ${ }^{55}$ Therefore, age-specific community-based seroprevalence studies of HEV infection are used to describe the sanitation level and public health status of a society. Overall, these studies have indicated that children in Iran are exposed to HEV and, therefore, preventive strategies are needed to reduce this exposure. ${ }^{5-57}$

\section{Diagnosis of HEV infection}

HEV causes a vast range of clinical presentations, which vary in severity from FLF, liver fibrosis and cirrhosis following chronic hepatitis $\mathrm{E}$, and acute icteric hepatitis to unapparent and asymptomatic infection. ${ }^{1,7,9,15,29,62}$ Most cases of hepatitis $\mathrm{E}$ among children are asymptomatic, ${ }^{27,39}$ and no cases of chronic hepatitis $\mathrm{E}$ have been reported in pregnant women and infants. ${ }^{38}$ Chronic HEV infection is, however, frequently observed among immunocompromised and immunosuppressed patients. ${ }^{7,9,14,29}$

The clinical manifestations of HEV infection are indistinguishable from clinical symptoms of the other viral hepatitis forms. ${ }^{35}$ In addition, these non-specific symptoms sometimes mask the diagnosis of HEV infection, making laboratory methods the most reliable criteria for diagnosis. The laboratory diagnosis methods are based on detection of HEV RNA in serum or stool samples by nucleic acid amplification techniques (NAT) or of anti-HEV antibodies in serum or plasma samples by serological tests (Fig. 3). ${ }^{1,5,17,63-65}$

The presence of HEV RNA in blood and stool is short-lived, and becomes undetectable in serum at 3-4 weeks and in stool at 6 weeks after the onset of clinical symptoms (Fig. 4). ${ }^{17,29}$ In asymptomatic subjects, viremia can last for 4-6 weeks. ${ }^{17}$ However, a prolonged viremia is also possible, especially among children following acute HEV infection and immunosuppressed patients. ${ }^{4,17}$ Anti-HEV IgM increases during the acute phase of infection. IgM level remains high for about 8 weeks, but declines rapidly and becomes undetectable in most patients after 3-8 months. 5,27 Meanwhile, long-lasting anti-HEV IgG antibodies appear shortly after the increase of IgM and persist for 1-14 years or more after the infection 


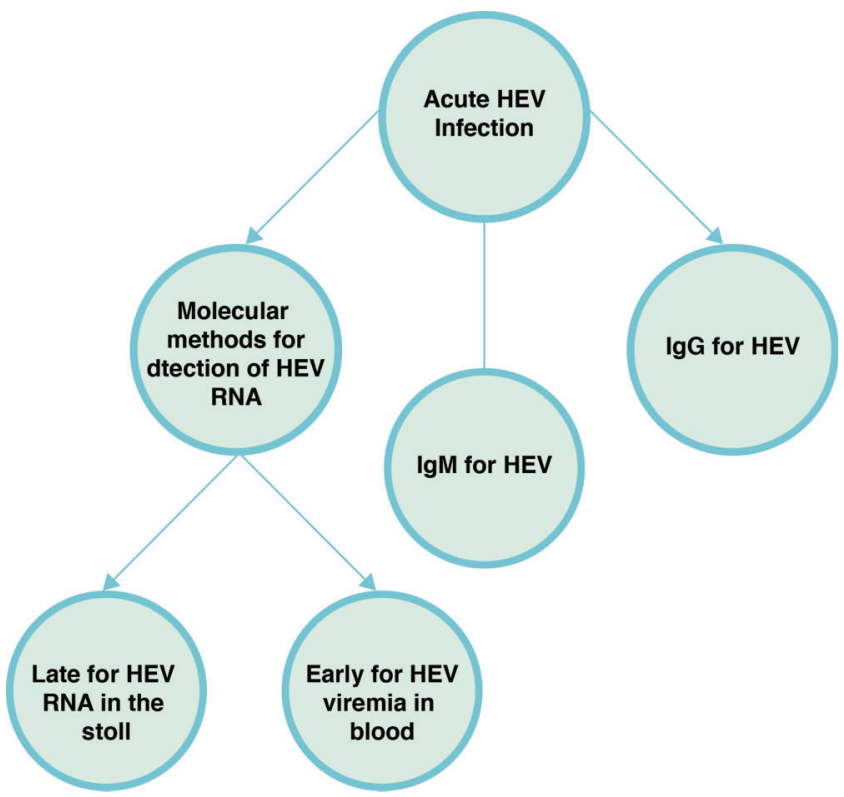

Fig. 3. Laboratory diagnosis of hepatitis E virus infection. ${ }^{38}$ (Adapted from Fig. 3 of reference 38 , with permission of the publisher).

(Fig. 4). ${ }^{5,29,63}$ Thus, detection of IgM is indicative of acute infection, and the presence of IgG is a sign of previous exposure to HEV. ${ }^{1,29}$

Evaluation of liver parameters is another diagnostic criterion. At onset of clinical symptoms, liver function tests show abnormal findings, such as for the measurements of aspartate aminotransferase (AST), alanine aminotransferase (ALT), alkaline phosphate, gamma-glutamyl transpeptidase and bilirubin. ${ }^{22,62}$ However, elevated levels of liver enzymes are
Taherkhani R. et al: HEV in pregnant women and children

short-lived and return to normal about 6 weeks after the onset of clinical symptoms. ${ }^{27}$

\section{Prevention and treatment of HEV infection}

The current preventive strategies primarily aim at reducing exposure to HEV by improving water supply facilities and sewage disposal systems, since the disease is predominantly transmitted via the faecal-oral route. ${ }^{17}$ Therefore, provision of safe water supplies, sanitary preparation of food, sanitary disposal of human waste and hygienic infrastructure appear to be the most effective preventive measures. ${ }^{1,5,22,30,37,66}$

Vaccination against HEV is another preventive strategy, although no commercial vaccine has yet become available worldwide. ${ }^{17}$ Several HEV vaccines have been designed and evaluated in the laboratory setting, including recombinant vaccines consisting of various truncated forms of the capsid protein (HEV 239, ${ }^{67}$ trpE-C2, ${ }^{68} 53 \mathrm{kDa},{ }^{69} \mathrm{pE2},{ }^{70} 56 \mathrm{kDa},{ }^{69}$ rHEV VLP, ${ }^{71} 62 \mathrm{kDa}^{72}$ and T1-ORF2 ${ }^{73}$ ), DNA vaccines (pcHEVORF2 and Lipo-NE-DP ${ }^{74-76}$ ) and, more recently, epitope-based vaccines. ${ }^{18,77}$ Amongst them, only one recombinant vaccine, the HEV 239 vaccine based on a $26 \mathrm{kDa}$ portion of the HEV capsid protein (aa 368-606), has been licensed by China's State Food and Drug Administration. ${ }^{3,18,78-81}$ Yet, this vaccine, despite showing promising results in human clinical trials, is not still approved for use in a susceptible population such as pregnant women, children and patients with pre-existing liver problems, and is not available worldwide. ${ }^{16,18,78}$

Upon disease emergence, the treatment strategy is usually supportive, as the disease is generally asymptomatic or selflimited at this stage. ${ }^{9,17,82}$ Antiviral treatment is administered only for patients with hepatic complications due to fulminant or chronic HEV infection. ${ }^{9,17}$ These antiviral therapies include monotherapy with pegylated interferon (PEG-IFN) or ribavirin, or combination therapy with these antiviral agents. $9,82,83$ Although these antiviral treatments result in clearance of the

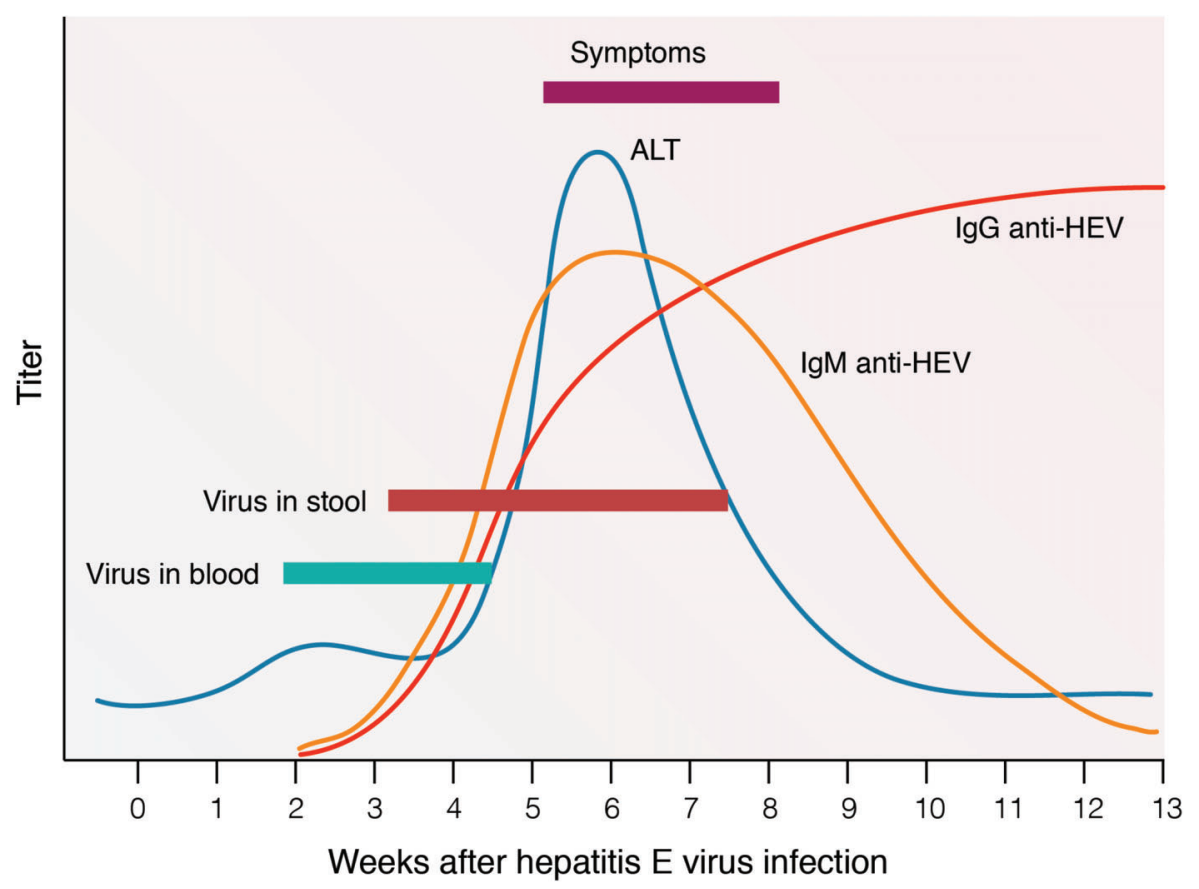

Fig. 4. Virological markers of hepatitis E virus infection. ${ }^{38}$ (Adapted from Fig. 2 of reference 38, with permission of the publisher). 
virus and reduction of the symptomatic period, they harbour their own limitations and side effects. ${ }^{26,83,84}$ PEG-IFN $\alpha$ has neuropsychiatric side effects and induces influenza-like symptoms, and ribavirin causes impaired renal function and anemia. ${ }^{83-85}$ Above all, these antiviral agents have teratogenic effects during pregnancy. ${ }^{9,38,84}$ Therefore, termination of pregnancy or early delivery of the foetus seems to be the most effective option to save mothers. ${ }^{38,39}$

\section{Conclusions}

This review has provided a general overview of the pathogenesis and epidemiology of HEV infection in pregnant women and children in Iran. HEV infection is generally a benign selflimited disease, but it can lead to serious consequences in susceptible populations such as pregnant women. It seems that a combination of host and viral factors contributes to the pathogenesis of hepatitis $E$ in pregnancy; although, the exact reason behind this excess severity during pregnancy is not yet fully understood.

HEV infection is an underestimated disease in Iran, most probably due to a lack of HEV consideration in the country's public health system. Despite being prevalent among children and pregnant women, our current knowledge regarding epidemiology of this viral infection in Iran is scarce. Therefore, further studies are required to more comprehensively determine the incidence and prevalence of HEV infection in these two groups in different regions of Iran. Once these data are obtained, the epidemiological pattern of this neglected infection in Iran will become clearer.

\section{Acknowledgments}

We would like to express our sincere gratitude to Professor Saeed Tajbakhsh, Head of the Department of Microbiology and Parasitology at the Bushehr University of Medical Sciences, for all of his support during the writing of this review.

\section{Conflict of interest}

None

\section{Author contributions}

Designing the study, collecting the data, drafting the manuscript and reading and approving the final draft of the manuscript (RT), designing the study, performing the literature review, drafting the manuscript, editing the manuscript and reading and approving the final draft of the manuscript (FF).

\section{References}

[1] Pérez-Gracia MT, García M, Suay B, Mateos-Lindemann ML. Current Knowledge on Hepatitis E. J Clin Transl Hepatol 2015;3:117-126. doi: 10.14218/ JCTH.2015.00009.

[2] Taherkhani R, Farshadpour F, Makvandi M, Rajabi Memari H, Samarbafzadeh $A R$, Sharifi $N$, et al. Cytokine profiles and cell proliferation responses to truncated ORF2 protein in Iranian patients recovered from hepatitis E infection. J Trop Med 2015;2015:523560. doi: 10.1155/2015/523560.

[3] Sridhar S, Lau SK, Woo PC. Hepatitis E: A disease of reemerging importance. J Formos Med Assoc 2015;114:681-690. doi: 10.1016/j.jfma.2015.02.003.

[4] Bajpai M, Gupta E. Transfusion-transmitted hepatitis E: is screening warranted? Indian J Med Microbiol 2011;29:353-358. doi: 10.4103/02550857.90158.
[5] Kamar N, Dalton HR, Abravanel F, Izopet J. Hepatitis E virus infection. Clin Microbiol Rev 2014;27:116-138. doi: 10.1128/CMR.00057-13.

[6] Rockville M. Topic I: Hepatitis E virus (HEV) and blood transfusion safety blood products advisory committee, 104th Meeting, September 20, 2012. FDA Fishers Lane Building 5630 Fishers Lane, Room 1066. 2012:1-24.

[7] Pischke S, Behrendt P, Bock CT, Jilg W, Manns MP, Wedemeyer H. Hepatitis E in Germany-an under-reported infectious disease. Dtsch Arztebl Int 2014; 111:577-583. doi: 10.3238/arztebl.2014.0577.

[8] Fujiwara S, Yokokawa Y, Morino K, Hayasaka K, Kawabata M, Shimizu T. Chronic hepatitis E: a review of the literature. J Viral Hepat 2014;21:78-89. doi: $10.1111 /$ jvh.12156.

[9] Lapa D, Capobianchi MR, Garbuglia AR. Epidemiology of hepatitis E virus in European countries. Int J Mol Sci 2015;16:25711-25743. doi: 10.3390/ ijms161025711.

[10] Hosseini Moghaddam SM. Hepatitis E virus and renal transplantation. Hepat Mon 2011;11:599-600. doi: 10.5812/kowsar.1735143X.

[11] Kamar N. Hepatitis e virus infection in Iranian kidney-transplant patients. Hepat Mon 2011;11:927-928. doi: 10.5812/kowsar.1735143X.

[12] Fierro NA, Realpe M, Meraz-Medina T, Roman S, Panduro A. Hepatitis E virus: An ancient hidden enemy in Latin America. World J Gastroenterol 2016;22: 2271-2283. doi: 10.3748/wjg.v22.i7.2271.

[13] Shrestha AC, Faddy HM, Flower RL, Seed CR, Keller AJ. Hepatitis E virus: do locally acquired infections in Australia necessitate laboratory testing in acute hepatitis patients with no overseas travel history? Pathology 2015; 47:97-100. doi: 10.1097/PAT.0000000000000229.

[14] Taherkhani R, Farshadpour F. Epidemiology of hepatitis E virus in Iran. World J Gastroenterol 2016;22:5143-5153. doi: 10.3748/wjg.v22.i22.5143.

[15] Bazerbachi F, Haffar S, Garg SK, Lake JR. Extra-hepatic manifestations associated with hepatitis E virus infection: a comprehensive review of the literature. Gastroenterol Rep (Oxf) 2016;4:1-15. doi: 10.1093/gastro/gov042.

[16] Kim JH, Nelson KE, Panzner U, Kasture Y, Labrique AB, Wierzba TF. A systematic review of the epidemiology of hepatitis E virus in Africa. BMC Infect Dis 2014;14:308. doi: 10.1186/1471-2334-14-308.

[17] Marano G, Vaglio S, Pupella S, Facco G, Bianchi M, Calizzani G, et al. Hepatitis $\mathrm{E}$ : an old infection with new implications. Blood Transfus 2015;13:6-17. doi: 10.2450/2014.0063-14.

[18] Taherkhani R, Farshadpour F. A new strategy for development of hepatitis $E$ vaccine: Epitope-based vaccines. Pathog Infect Dis 2015;1:e933.

[19] World Health Organization. Hepatitis E, WHO fact sheet; No. 280, updated July 2015. Available at: http://www.who.int/mediacentre/factsheets/fs280/en.

[20] World Health Organization. Viral hepatitis report by the Secretariat; A62/22. Available at: apps.who.int/gb/ebwha/pdf files/A62/A62 22-en.pdf.

[21] Khuroo MS, Khuroo MS. Hepatitis E: an emerging global disease - from discovery towards control and cure. J Viral Hepat 2016;23:68-79. doi: 10. $1111 /$ jvh.12445.

[22] Teshale EH, Hu DJ. Hepatitis E: Epidemiology and prevention. World J Hepatol 2011;3:285-291. doi: 10.4254/wjh.v3.i12.285.

[23] Tian DY, Chen Y, Xia NS. Significance of serum IgA in patients with acute hepatitis E virus infection. World J Gastroenterol 2006;12:3919-3923. doi: 10.3748/wjg.v12.i24.3919.

[24] Farshadpour F, Taherkhani R, Makvandi M, Rajabi Memari H, Samarbafzadeh AR. Codon-optimized expression and purification of truncated ORF2 protein of hepatitis E virus in escherichia coli. Jundishapur J Microbiol 2014;7: e11261. doi: $10.5812 / \mathrm{jjm}$.

[25] Wang L, Zhuang H. Hepatitis E: an overview and recent advances in vaccine research. World J Gastroenterol 2004;10:2157-2162.

[26] Lee GY, Poovorawan K, Intharasongkroh D, Sa-Nguanmoo P, Vongpunsawad S, Chirathaworn $\mathrm{C}$, et al. Hepatitis E virus infection: Epidemiology and treatment implications. World J Virol 2015;4:343-355.10.5501/wjv.v4.i4.343.

[27] Verghese VP, Robinson JL. A systematic review of hepatitis E virus infection in children. Clin Infect Dis 2014;59:689-697. doi: 10.1093/cid/ciu371.

[28] Farshadpour F, Makvandi M, Taherkhani R. Design, construction and cloning of truncated ORF2 and tPAsp-PADRE-truncated ORF2 gene cassette from hepatitis $\mathrm{E}$ virus in the pVAX1 expression vector. Jundishapur J Microbiol 2015;8:e26035. doi: 10.5812/jjm.

[29] Ahmed A, Ali IA, Ghazal H, Fazili J, Nusrat S. Mystery of hepatitis E virus: recent advances in its diagnosis and management. Int J Hepatol 2015;2015: 872431. doi: $10.1155 / 2015 / 872431$.

[30] Mushahwar IK. Hepatitis E virus: molecular virology, clinical features, diagnosis, transmission, epidemiology, and prevention. J Med Virol 2008;80: 646-658. doi: 10.1002/jmv.21116.

[31] Yazbek S, Kreidieh K, Ramia S. Hepatitis E virus in the countries of the Middle East and North Africa region: an awareness of an infectious threat to blood safety. Infection 2016;44:11-22. doi: 10.1007/s15010-015-0807-5.

[32] Dalton HR, Bendall R, Ijaz S, Banks M. Hepatitis E: an emerging infection in developed countries. Lancet Infect Dis 2008;8:698-709. doi: 10.1016/ S1473-3099(08)70255-X.

[33] Sayed IM, Vercauteren K, Abdelwahab SF, Meuleman P. The emergence of hepatitis E virus in Europe. Future Virology 2015;10:763-778. doi: 10.2217/ fvl.15.29. 
[34] Jamali R. Epidemiologic studies on viral hepatitis: a short review. Thrita 2014;3:e15376. doi: 10.5812/thrita.15376.

[35] Farshadpour F, Taherkhani R, Makvandi M. Prevalence of hepatitis E virus among adults in south-west of Iran. Hepat Res Treat 2015;2015:759589. doi: $10.1155 / 2015 / 759589$.

[36] Ahmadi Ghezeldasht S, Miri R, Hedayatimoghadam M, Shamsian A, Bidkhori H, Fathimoghadam $F$, et al. Population movement and virus spreading: HEV spreading in a Pilgrimage city, Mashhad in northeast Iran; an example. Hepat Mon 2013;13:e10255. doi: 10.5812/hepatmon.10255.

[37] Chaudhry SA, Verma N, Koren G. Hepatitis E infection during pregnancy. Can Fam Physician 2015;61:607-608.

[38] El Sayed Zaki M, El Razek MM, El Razek HM. Maternal-fetal hepatitis E transmission: is it underestimated? J Clin Transl Hepatol 2014;2:117-123. doi: 10.14218/JCTH.2014.00006.

[39] Navaneethan U, Al Mohajer M, Shata MT. Hepatitis E and pregnancy: understanding the pathogenesis. Liver Int 2008;28:1190-1199. doi: 10.1111/j. 1478-3231.2008.01840.x.

[40] Kumar A, Begum N. Hepatitis E in pregnancy: an insight into etiopathogenesis. JIMSA 2010;23:281-283.

[41] Taherkhani R, Makvandi M, Farshadpour F. Development of enzyme-linked immunosorbent assays using 2 truncated ORF2 proteins for detection of IgG antibodies against hepatitis E virus. Ann Lab Med 2014;34:118-126. doi: 10.3343/alm.2014.34.2.118.

[42] Kar P. Hepatitis E virus infection during pregnancy: why is the disease stormy? Medicine Update 2012;22:459-462.

[43] Bernuau J, Nicand E, Durand F. Hepatitis E-associated acute liver failure in pregnancy: an Indian puzzle. Hepatology 2008;48:1380-1382. doi: 10. 1002/hep.22619.

[44] Navaneethan U. Seroprevalence of hepatitis E infection in pregnancy - more questions than answers. Indian J Med Res 2009;130:677-679.

[45] Rostamzadeh Khameneh Z, Sepehrvand N, Khalkhali HR. Seroprevalence of hepatitis E among pregnant women in Urmia, Iran. Hepat Mon 2013;13: e10931. doi: 10.5812/hepatmon.10931.

[46] Rasti M, Samarbafzadeh A, Neisi N, Makvandi M, Najafifard S, Sharifat M, et al. Study on the seroprevalence of hepatitis $E$ virus infection in pregnant women referring to Imam Khomeini general hospital in Ahvaz. Jentashapir J Health Res 2014;5:101-105.

[47] Mamani M, Zamani M, Hashemi SH, Keramat F. Seroprevalence of antibodies to hepatitis E virus among pregnant women. Avicenna J Clin Microbiol Infect 2015;2:e25339. doi: 10.17795/ajcmi-25339.

[48] Tabarraei A, Moradi A, Rodgari D, Javid N, Bakhshandeh Nosrat S. Antihepatitis E virus seroprevalence in pregnant women, in Gorgan, Iran, North East of Caspian Sea. International Conference on Life Science and Technology, Singapore 2011.

[49] Moradi A, Besharat S, Minaiifar MM, Roshandel G, Tabaraii A. Seroepidemiologic assessment of hepatitis E virus in women of reproductive age, Gorgan. Zahedan J Res Med Sci 2010;12:44-47.

[50] Begum N, Devi SG, Husain SA, Ashok K, Kar P. Seroprevalence of subclinical HEV infection in pregnant women from north India: a hospital based study. Indian J Med Res 2009;130:709-713.

[51] Stoszek SK, Abdel-Hamid M, Saleh DA, El Kafrawy S, Narooz S, Hawash $Y$, et al. High prevalence of hepatitis $E$ antibodies in pregnant Egyptian women. Trans R Soc Trop Med Hyg 2006;100:95-101. doi: 10.1016/j.trstmh.2004. 12.005 .

[52] Adjei AA, Tettey Y, Aviyase JT, Adu-Gyamfi C, Obed S, Mingle JA, et al. Hepatitis $E$ virus infection is highly prevalent among pregnant women in Accra, Ghana. Virol J 2009;6:108. doi: 10.1186/1743-422X-6-108.

[53] Kumar RM, Uduman S, Rana S, Kochiyil JK, Usmani A, Thomas L. Seroprevalence and mother-to-infant transmission of hepatitis $E$ virus among pregnant women in the United Arab Emirates. Eur J Obstet Gynecol Reprod Biol 2001;100:9-15. doi: 10.1016/S0301-2115(01)00448-1.

[54] Oncu S, Oncu S, Okyay P, Ertug S, Sakarya S. Prevalence and risk factors for HEV infection in pregnant women. Med Sci Monit 2006;12:CR36-39.

[55] Saffar MJ, Farhadi R, Ajami A, Khalilian AR, Babamahmodi F, Saffar H. Seroepidemiology of hepatitis E virus infection in 2-25-year-olds in Sari district, Islamic Republic of Iran. East Mediterr Health J 2009;15:136-142.

[56] Shamsizadeh A, Nikfar R, Makvandi M, Shamsizadeh N. Seroprevalence of hepatitis $E$ virus infection in children in the Southwest of Iran. Hepat Mon 2009;9:261-264.

[57] Reza Sharif A, Reza Sharif M, Taghavi Ardekani A, Madani M, Kheirkhah D, Afzali H. Seroepidemiology of hepatitis $E$ in children of Kashan, 2012. Iranian J Infect Dis Trop Med 2014;18:31-36.

[58] Ataei B, Nokhodian Z, Javadi AA, Kassaian N, Shoaei P, Farajzadegan Z, et al. Hepatitis E virus in Isfahan Province: a population-based study. Int J Infect Dis 2009;13:67-71. doi: 10.1016/j.ijid.2008.03.030.

[59] Asaei S, Ziyaeyan M, Moeini M, Jamalidoust M, Behzadi MA. Seroprevalence of hepatitis $A$ and $E$ virus infections among healthy population in Shiraz, Southern Iran. Jundishapur J Microbiol 2015;8:e19311. doi: 10.5812/jjm. $19311 \mathrm{v} 2$.
[60] Fix AD, Abdel-Hamid M, Purcell RH, Shehata MH, Abdel-Aziz F, Mikhail N, et al. Prevalence of antibodies to hepatitis $\mathrm{E}$ in two rural Egyptian communities. Am J Trop Med Hyg 2000;62:519-523.

[61] Taremi M, Mohammad Alizadeh AH, Ardalan A, Ansari S, Zali MR. Seroprevalence of hepatitis $E$ in Nahavand, Islamic Republic of Iran: a population-based study. East Mediterr Health J 2008;14:157-162.

[62] Teshale EH, Hu DJ, Holmberg SD. The two faces of hepatitis E virus. Clin Infect Dis 2010;51:328-334. doi: 10.1086/653943.

[63] Vasickova P, Psikal I, Kralik P, Widen F, Hubalek Z, Pavlik I. Hepatitis E virus: a review. Veterinarni Medicina 2007;52:365-384.

[64] Aggarwal R. Diagnosis of hepatitis E. Nat Rev Gastroenterol Hepatol 2013; 10:24-33. doi: 10.1038/nrgastro.2012.187.

[65] Dreier J, Juhl D. Autochthonous hepatitis e virus infections: a new transfusionassociated risk? Transfus Med Hemother 2014;41:29-39. doi: 10.1159/ 000357098.

[66] Shahzad F, Atiq M, Ejaz S, Hameed S. Hepatitis E: review of a disease endemic in Pakistan. J Pak Med Assoc 2001;51:166-169.

[67] Li SW, Zhang J, Li YM, Ou SH, Huang GY, He ZQ, et al. A bacterially expressed particulate hepatitis $\mathrm{E}$ vaccine: antigenicity, immunogenicity and protectivity on primates. Vaccine 2005;23:2893-2901. doi: 10.1016/j.vaccine.2004.11.064.

[68] Purdy MA, McCaustland KA, Krawczynski K, Tam A, Beach MJ, Tassopoulos $\mathrm{NC}$, et al. Expression of a hepatitis $\mathrm{E}$ virus (HEV)-trpE fusion protein containing epitopes recognized by antibodies in sera from human cases and experimentally infected primates. Arch Virol 1992;123:335-349. doi: 10.1007/ BF01317268.

[69] Robinson RA, Burgess WH, Emerson SU, Leibowitz RS, Sosnovtseva SA, Tsarev $\mathrm{S}$, et al. Structural characterization of recombinant hepatitis $\mathrm{E}$ virus ORF2 proteins in baculovirus-infected insect cells. Protein Expr Purif 1998; 12:75-84. doi: 10.1006/prep.1997.0817.

[70] Zhang JZ, Ng MH, Xia NS, Lau SH, Che XY, Chau TN, et al. Conformational antigenic determinants generated by interactions between a bacterially expressed recombinant peptide of the hepatitis $\mathrm{E}$ virus structural protein. J Med Virol 2001;64:125-132. doi: 10.1002/jmv.1027.

[71] Li TC, Takeda N, Miyamura T, Matsuura Y, Wang JC, Engvall H, et al. Essential elements of the capsid protein for self-assembly into empty virus-like particles of hepatitis E virus. J Virol 2005;79:12999-13006. doi: 10.1128/JVI. 79.20.12999-13006.2005.

[72] McAtee CP, Zhang Y, Yarbough PO, Fuerst TR, Stone KL, Samander S, et al. Purification and characterization of a recombinant hepatitis $E$ protein vaccine candidate by liquid chromatography-mass spectrometry. J Chromatogr B Biomed Appl 1996;685:91-104. doi: 10.1016/0378-4347(96)00143-0.

[73] Huang WJ, Zhang HY, Harrison TJ, Lan HY, Huang GY, Wang YC. Immunogenicity and protective efficacy in rhesus monkeys of a recombinant ORF2 protein from hepatitis E virus genotype 4. Arch Virol 2009;154:481-488. doi: 10.1007/s00705-009-0335-7.

[74] Kamili S, Spelbring J, Carson D, Krawczynski K. Protective efficacy of hepatitis $E$ virus DNA vaccine administered by gene gun in the cynomolgus macaque model of infection. J Infect Dis 2004;189:258-264. doi: 10.1086/380801.

[75] Kamili S, Spelbring J, Krawczynski K. DNA vaccination against hepatitis E virus infection in cynomolgus macaques. J Gastroenterol Hepatol 2002;17 Suppl 3:S365-S369. doi: 10.1046/j.1440-1746.17.s3.29.x.

[76] Arankalle VA, Lole KS, Deshmukh TM, Srivastava S, Shaligram US. Challenge studies in Rhesus monkeys immunized with candidate hepatitis $E$ vaccines: DNA, DNA-prime-protein-boost and DNA-protein encapsulated in liposomes. Vaccine 2009;27:1032-1039. doi: 10.1016/j.vaccine.2008.11.097.

[77] Taherkhani R, Farshadpour F, Makvandi M. Design and production of a multiepitope construct derived from hepatitis E virus capsid protein. J Med Virol 2015;87:1225-1234. doi: 10.1002/jmv.24171.

[78] Wu T, Li SW, Zhang J, Ng MH, Xia NS, Zhao Q. Hepatitis E vaccine development: a 14 year odyssey. Hum Vaccin Immunother 2012;8:823-827. doi: 10.4161/hv.20042.

[79] Zhang J, Liu CB, Li RC, Li YM, Zheng YJ, Li YP, et al. Randomized-controlled phase II clinical trial of a bacterially expressed recombinant hepatitis $\mathrm{E}$ vaccine. Vaccine 2009;27:1869-1874. doi: 10.1016/j.vaccine.2008.12.061.

[80] Zhang J, Shih JW, Wu T, Li SW, Xia NS. Development of the hepatitis E vaccine: from bench to field. Semin Liver Dis 2013;33:79-88. doi: 10.1055/ s-0033-1338116.

[81] Zhu FC, Zhang J, Zhang XF, Zhou C, Wang ZZ, Huang SJ, et al. Efficacy and safety of a recombinant hepatitis $E$ vaccine in healthy adults: a large-scale, randomised, double-blind placebo-controlled, phase 3 trial. Lancet 2010; 376:895-902. doi: 10.1016/S0140-6736(10)61030-6.

[82] Abbas Z, Afzal R. Hepatitis E: when to treat and how to treat. Antivir Ther 2014;19:125-131. doi: 10.3851/IMP2705.

[83] Nijskens CM, Pas SD, van der Eijk AA, de Man RA. Hepatitis E in Europe: diagnosis and treatment. EMJ Gastroenterol 2015;4:121-127.

[84] Debing Y, Neyts J. Antiviral strategies for hepatitis E virus. Antiviral Res 2014; 102:106-118. doi: 10.1016/j.antiviral.2013.12.005.

[85] Peters van Ton AM, Gevers TJ, Drenth JP. Antiviral therapy in chronic hepatitis E: a systematic review. J Viral Hepat 2015;22:965-973. doi: 10.1111/jvh. 12403. 